\title{
EDITORIAL
}

\section{Direct amplification of Mycobacterium tuberculosis deoxyribonucleic acid in paucibacillary tuberculosis}

\author{
C. Saltini
}

The discovery of the polymerase chain reaction (PCR) as a means to generate detectable signals from as little as a single molecule of target deoxyribonucleic acid (DNA) [1] has led to the development of extremely powerful and rapid diagnostic tests for a number of infectious agents. PCR was therefore expected to improve significantly the sensitivity of tests for the diagnosis of tuberculosis (TB), compared with the standard stains for acid fast bacilli (AFB) on sputum smears. Since the first report by HANCE $e t$ al. [2] on the use of PCR amplification of the $65 \mathrm{kDa}$ heat shock protein (HSP) gene for the diagnosis of Mycobacterium tuberculosis in clinical samples, a number of $M$. tuberculosis DNA sequences have been tested as amp-lification targets [3]. Over the past ten years, several PCR test formats have been employed and nested PCR tests have been described which were endowed with a detec-tion power 1,000-fold greater (lower detection limit, $0.1 \mathrm{M}$. tuberculosis colony-forming unit (cfu) $\left.\mathrm{mL}^{-1}\right)$ than that of the standard PCR with 35 amplification cycles (detection limit, $\left.100 \mathrm{cfu} \cdot \mathrm{mL}^{-1}\right)$ [4].

Among DNA targets, the IS6110 insertion sequence, a $M$. tuberculosis complex-specific sequence which is repeated 10-16 times in the chromosome of M. tuberculosis [5], has been the most widely used. This test has the power of amplifying a fraction of a chromosome of $M$. tuberculosis and with this test it has been possible to accomplish something as spectacular as identifying mycobacteria buried in mummies thousands of years old [6]. However, the test is difficult to handle and its reproducibility across laboratories has been rather disappointing [7]. Even more importantly, all the amplification tests using either the PCR or other ribonucleic acid (RNA) and DNA amplification techniques that have been developed, bottled and marketed for the diagnosis of $M$. tuberculosis in routine laboratories do not seem sufficiently sensitive for the diagnosis of paucibacillary TB. Notwithstanding their extreme power in the laboratory setting and although the rapid amplification tests are more sensitive than AFB stains, home grown and commercial tests alike, both still fail to diagnose about $50 \%$ of microscopy-negative sputum samples [8] i.e., those samples containing less than the 5-10,000 M. tuberculosis organisms $\cdot \mathrm{mL}^{-1}$ of sample that are required for a positive AFB smear.

With this background, an American Thoracic Society (ATS) panel recently recommended that the rapid amplification tests should be used for the confirmation of rapid diagnosis of M. tuberculosis versus nontuberculous myco-

Correspondence: C. Saltini, Divisione di Tisiologia e Malattie dell'Apparato Respiratorio, Policlinico, via del Pozzo 71, 41100 Modena, Italy. Fax: 3959424231 bacteria in individuals with an AFB-positive sputum smear. With a direct amplification test it can be rapidly determined (with $>95 \%$ sensitivity) whether an individual has active, multibacillary TB (requiring isolation and contact screening), or a nontuberculous mycobacterial infection (not requiring any of the above). In contrast, the same ATS panel could not recommend the use of rapid amplification tests for the routine diagnosis of paucibacillary TB, due to their lower sensitivity in the setting of AFB negative sputum samples [8].

The majority of studies evaluating the clinical utility of DNA or RNA amplification tests for the diagnosis of TB have dealt with respiratory samples from pulmonary TB patients. Interest for pulmonary TB stems not only from the notion that pulmonary TB represents the most common localization of the infection, but also that these patients are the major source of $M$. tuberculosis transmission. In this context, rapid diagnosis of pulmonary TB is critical both for the respiratory physician and the public health officer. However, relative to the more common cavitary TB, extrapulmonary TB represents a difficult diagnostic challenge since the clinical presentation of extrapulmonary TB is not always as typical. Furthermore, as extrapulmonary TB is most often paucibacillary, AFB stains are even less sensitive on fluid aspirates and tissue biopsies than they are on sputum samples. In this context, improved microbiological diagnosis would be of great import since the appearance of a caseating granuloma in affected tissues or the crowding of lymphocytes in an aspirated fluid may be the only evidence for extrapulmonary TB.

A variety of rapid amplification tests have been proposed for the diagnosis of nonrespiratory TB. DAlLLoux and LaURAIN [9], using both the Roche Amplicor PCR system (Roche, Basel, Switzerland) and the Genprobe AMTD RNA amplification system (Genprobe, San Diego, CA, USA), obtained a positive test in only $60 \%$ of nonrespiratory specimens compared to $90 \%$ of respiratory specimens. TORTOLI et al. [10] reported similar results using a ligase chain reaction test on a variety of extrapulmonary specimens with which they had $73 \%$ positives, compared to $98 \%$ positives with respiratory samples. TAN et al. [11] developed a very sensitive test yielding $100 \%$ sensitivity on a variety of extrapulmonary specimens, but with disappointing specificity $(88 \%$ for bronchoalveolar lavage and pleural fluid and $85 \%$ for other extrapulmonary samples, compared with $95 \%$ for sputum samples). With regard to specific extrapulmonary sites, QuERoL et al. [12] obtained $81 \%$ sensitivity in the diagnosis of pleural effusions with the IS6110 PCR test compared to 14\% with the ZiehlNeelsen stain. Similarly, Mangiapan et al. [13] were able to 
amplify M. tuberculosis DNA in 13 of 17 cases of tuberculous pleurisy, thereby identifying 10 of 14 culture-negative effusions using a very sensitive capture assay applied to the IS6110 PCR test.

Among extrapulmonary samples, the blood has been sought as the ideal specimen with which to diagnose disseminated TB in human immunodeficiency virus (HIV) infected patients. ConDos et al. [14] used the IS6110 PCR test in blood and obtained an outstanding sensitivity (95\%) with poor specificity $(89 \%)$. Blood testing has also been explored by FolgueIRA et al. [15] who showed a sensitivity of $82 \%$ in HIV-infected and of $33 \%$ in HIV-seronegative patients with an 8-fold greater sensitivity than $M$. tuberculosis cultures. Similar results were obtained by DEL PRETE $e t$ al. [16] who amplified the IS6110 sequence in $86 \%$ of 30 blood samples from TB patients and by GAMBOA et al. [17] who amplified $M$. tuberculosis RNA from $90 \%$ of TB patient blood samples with the amplified mycobacteria direct test (AMTD).

In the study presented in this issue of the Journal, KoLK et al. [18] analyse the performance of a home grown amplification test using PCR for the amplification of the IS6110 repeated sequence in the diagnosis of extrapulmonary $\mathrm{TB}$, in comparison to the "standard" rapid tests i.e., microscopy for AFB by Auramine and Ziehl-Neelsen stains. The test used in this study was supported by the best possible controls for false negative results. By examining in detail nonrespiratory specimens including pleural fluid, tissue biopsies, blood, pus, bone marrow, ascites, synovial fluid, urine and faeces, the authors were able to establish a sensitivity of $86 \%$ (with a specificity of 92\%) for the PCR amplification test which is well above that of the AFB stains (31\% sensitivity and $94 \%$ specificity, in this study).

The study was carried out in a laboratory involved for many years in the development, clinical application, standardization and quality control of molecular diagnosis of $M$. tuberculosis, therefore, it may give us a good approximation of what current rapid amplification tests could do for the diagnosis of paucibacillary TB, when carried out in a laboratory with high quality standards. Firstly, the observation that despite a well performing test not all specimen types can be diagnosed with equal sensitivity. It tells us that more work must be done to adapt amplification tests to each type of specimen that needs to be examined in order to diagnose extrapulmonary TB. In the context of the reports on $M$. tuberculosis DNA amplification from blood samples quoted above [14-17], the fact that the IS6110 test used by KoLK et al. [18] correctly diagnosed almost all of the pus specimens and a good percentage of the pleural fluids, but virtually none of the blood samples suggests that specimen preparation, in addition to DNA amplification can still be improved.

Secondly, with the DNA amplification test described in this issue of the Journal, KoLK et al. [18] were not only able to predict TB in $86 \%$ of their extrapulmonary cases (of whom only $31 \%$ were AFB positive), they were also able to predict TB in about $50 \%$ of patients with a clinical presentation consistent with TB who responded to a trial of antituberculous therapy, but turned out to have negative $M$. tuberculosis cultures thereby receiving an "empirical" diagnosis of TB. Would the clinician be $100 \%$ confident that the test is both sensitive and specific, most of the "empirical" could be taken out of TB diagnosis.
Are the direct amplification tests of today what pulmonary and infectious disease physicians need for the rapid routine diagnosis of paucibacillary TB? The answer is both yes and no.

Yes, because with a quality controlled microbiology laboratory, these tests could help to confidently diagnose TB within a week from admission. However, as the ATS panel has suggested, rapid amplification testing in AFBnegative paucibacillary TB, be it pulmonary or extrapulmonary, needs to be carried out in clinical centres where criteria for empirical diagnosis of TB are standardized, molecular testing is quality controlled, and the clinician and the microbiologist work in a "controlled clinical trial" mode until both clinical and molecular tests are rigorously standardized and validated.

No, because as the NoordноEк et al. [7] multicentre study demonstrated (in which the Author of this study participated), these tests are not reproducible in all laboratories and both sensitivity and specificity may be so terrible in a poorly performing laboratory, that either no patient with tuberculosis would end up with the right treatment or a host of nontuberculosis patients would receive a diagnosis of tuberculosis and a six month course of three-drug antituberculous therapy.

\section{References}

1. Saiki RK, Scharf S, Faloona F, et al. Enzymatic amplification of $\beta$-globin genomic sequences and restriction site analysis for diagnosis of sickle cell anemia. Science 1985; 230: 1350-1354.

2. Hance AJ, Grandchamp B, Lèvy-Frébault V, et al. Detection and identification of mycobacteria by amplification of mycobacterial DNA. Mol Microbiol 1989; 3: 843-849.

3. Richeldi L, Barnini S, Saltini C. Molecular diagnosis of tuberculosis. In: Saltini C, Ivanyi J, eds. Advances in Research and Control of Tuberculosis. Eur Respir J 1995; 8: Suppl., 689s-700s.

4. Miyazaky Y, Koga H, Kohno S, Kaku M. Nested polymerase chain reaction for detection of Mycobacterium tuberculosis in clinical samples. J Clin Microbiol 1993; 31: 2228-2232.

5. Eisenach KD, Sifford MD, Cave MD, Bates JH, Crawford JT. Detection of Mycobacterium tuberculosis in sputum samples using a polymerase chain reaction. Am Rev Respir Dis 1991; 144: 1160-1163.

6. Salo WL, Aufderheide AC, Buikstra J, Holcomb TA. Identification of Mycobacterium tuberculosis DNA in a pre-Columbian Peruvian mummy. Proc Natl Acad Sci USA 1994; 91: 2091-2094.

7. Noordhoek GT, Van Embden JDA, Kolk AHJ. Reliability of nucleic acid amplification for detection of Mycobacterium tuberculosis: an international collaborative quality control study among 30 laboratories. J Clin Microbiol 1996; 34: 2522-2525.

8. American Thoracic Society Workshop. Rapid diagnostic tests for tuberculosis. What is the appropriate use? Am J Respir Crit Care Med 1997; 55: 1804-1814.

9. Dailloux M, Laurain C. Value of nucleic acid amplification methods Amplicor (Roche) and Amplified MTD (Gen-Probe) for the rapid diagnosis of tuberculosis. Ann Biol Clin Paris 1996; 54: 297-301.

10. Tortoli E, Lavinia F, Simonetti T. Evaluation of a commercial ligase chain reaction kit (Abbott LCx) for direct 
detection of Mycobacterium tuberculosis in pulmonary and extrapulmonary samples. J Clin Microbiol 1997; 35: 2424-2426.

11. Tan MF, Ng WC, Chan SH, Tan WC. Comparative usefulness of PCR in the detection of Mycobacterium tuberculosis in different clinical specimens. J Med Microbiol 1997; 46: 164-169.

12. Querol MJ, Minguez J, Garcia-Sanchez E, Farga MA, Gimeno C, Garcia de Lomas J. Rapid diagnosis of pleural tuberculosis by polymerase chain reaction. Am J Respir Crit Care Med 1995; 152: 1977-1981.

13. Mangiapan G, Vokurka M, Schouls L, et al. Sequence capture-PCR improves detection of mycobacterial DNA in clinical specimens. J Clin Microbiol 1996; 34: 12091215.

14. Condos R, McClune A, Rom WN, Schluger NW. Peripheral-blood-based PCR assay to identify patients with active pulmonary tuberculosis. Lancet 1996; 347: 1082-1085.
15. Folgueira L, Delgado R, Palenque E, Aguado JM, Noriega AR. Rapid diagnosis of Mycobacterium tuberculosis bacteremia by PCR. J Clin Microbiol 1996; 34: 512-515.

16. Del Prete R, Mosca A, D'Alagni M, Sabato R, Picca V, Miragliotta G. Detection of Mycobacterium tuberculosis DNA in blood of patients with acute pulmonary tuberculosis by polymerase chain reaction and non-isotopic hybridisation assay. J Med Microbiol 1997; 46: 495-500.

17. Gamboa F, Manterola JM, Lonca J, et al. Detection and identification of mycobacteria by amplification of RNA and DNA in pretreated blood and bone marrow aspirates by a simple lysis method. J Clin Microbiol 1997; 35 : 2124-2128.

18. Kolk AHJ, Kox LFF, van Leeuwen J, Kujiper S, Jansen HM. Clinical utility of the polymerase chain reaction in the diagnosis of extrapulmonary tuberculosis. Eur Respir $J$ 1998; 11: 1222-1226. 